\title{
Edited Transcript of AALS-AEA Conference on Products Liability
}

\author{
Henry G. Manne, editort
}

Roland McKean. ${ }^{1}$ Professor Buchanan's comments on the defense of caveat emptor posed few issues with which I would disagree. Using different terminology, I did make the central point that caveat emptor as the basis for products liability does at least lower certain costs in connection with certain product categories. That does not mean that there is a clear-cut case that any logical man must accept for approving caveat emptor. It just means that there are certain consequences of having that arrangement that can logically be agreed upon.

Professor Calabresi perceptively emphasized categories of products as the correct approach to a fuller discussion of products liability. I did say that for some products one might prefer caveat emptor while for other products one might prefer government intervention or producer liability. But I did neglect the analysis of particular product categories, aside from choosing specific examples from different product categories to illustrate different points. This is a direction in which one could profitably move. For particular kinds of product categories what would the costs be of having different liability assignments, different arrangements? Calabresi has made some progress in that direction, and my hunch is that we can profitably go still further and look at the categories in greater detail.

A minor matter of disagreement between Calabresi and myself might occur in connection with this idea of trading fairness for efficiency. I think of myself as occasionally making a trade-off of what I consider a fair or equitable arrangement for a bit of something else-greater efficiency or some other objective. If there were really and truly zero transaction costs, we would not have to make that trade-off. But since there are not zero costs, I think sometimes one is forced to ask himself would he prefer an arrangement which corresponds more closely to what he would regard as equitable, or would he prefer another arrangement which gives up a little equity for some other objective. Now

† Kenan Professor of Law, Department of Political Science, University of Rochester.

1 Professor of Economics, University of Virginia. 
Professor Calabresi prefers to look at this in a different way, but it seemed to me that we were not really in substantial disagreement about this. The disagreement was a minor one about the terminology or a particular way of looking at the matter and not about the substance.

One of the critics apparently concluded that I felt that caveat emptor was always the best arrangement. I do not really believe that, at least with respect to all product categories. I expect the idea emerged because the bulk of my analysis was devoted to "let-the-buyer-beware," and I may have sounded as though I really thought that was the best arrangement. I meant, however, to convey that one can prefer any one of these arrangements without being illogical. We just do not have any criterion dictating what is the best arrangement from some group standpoint.

There seemed to be some doubt whether, if we do not have any criterion for what is good, the matter need be discussed at all. Actually, however, all any science can do is to throw a little more information in the pot to help each of us determine his preference. I do not believe that is useless even though one cannot say precisely what is the optimal policy from everyone's standpoint.

I was a bit shaken to realize that Professor Dorfman thought I was applying the Coase theorem and leaving it at that. He seemed to be regarding me as saying, in accord with the Coase theorem, that the liability assignment really does not make any difference in the real world. This may have resulted because the bulk of the discussion was devoted to an elaboration of notions of comparative advantage in the zero transaction costs case. I regard the Coase theorem as an important point of departure from which to go forward into the real world and ask which arrangement most reduces total costs in comparison with other arrangements for a particular product category. I did not devote as much space as I might have to the analysis of these pertinent issues.

Professor Gilmore felt that I was remiss in saying there had not already been an important revolution in products liability developments. Certainly there has been a revolution in a legal sense, and most people would say that the changes within the last fifty years have been great compared to the changes in the previous century or so. But from the standpoint of the economic implications of the alternative arrangements, changes so far strike me as having been fairly modest, particularly in comparison with some of the proposals that are being discussed, such as really strict liability, perhaps with no requirement of a defect, or a more extreme arrangement, social insurance for all accident victims. These, I think, would have quite important economic 
implications, while the changes so far in the direction of producer liability do not strike me as having had crucial economic implications.

I think it may have been Professor Gilmore too who felt that since the Coase theorem was only taken as a point of departure which did not necessarily give real world implications, that maybe it was of little relevance. I do not agree. I think that this theorem, even though it is far from having assumptions that correspond to the real world, is terribly important in thinking about liability or property rights assignments and things of that sort. But, I emphasize again, it is only a point of departure.

The real disagreements will regard the criterion. Some people will say economic efficiency is the most important. Others would rather put more emphasis on equity, even if they have to sacrifice a good deal of efficiency. Some will simply have a wish to interfere with other people's choices, while others find it intolerable to tell somebody else what is good for him.

JAMES Buchanan. ${ }^{2}$ In one sense $I$ am in a fair degree of agreement not only with McKean but with Dorfman and Calabresi, if you properly delineate the issues. My paper really takes off from one aspect of the general problem that McKean mentioned in his basic monograph but did not develop fully. And, I think, Professor Dorfman largely assumes away the issues that $\mathrm{I}$ discuss. $\mathrm{He}$ in a sense assumes away the possibility of putting liability on the producers, if in fact the producer had no fault, whereas I emphasize the inherent possibility of the pure accident as an aspect of the product. And, I am not in disagreement essentially with Professor Calabresi either, since he too assumes away the problem I was discussing. He discusses the most effective costreducing assignment of liability on the presumption that the technology of the product, or, I should say, the quality of the product, is fixed. Only if you define a fixed product quality, in a world where transaction costs exist, does it seem to me that Calabresi's problem arises. Then I think I would agree that we should search for the costminimizing way of assigning the liability. I was emphasizing that the assignment of liability may in fact itself affect the quality of the product. So in a sense I do not disagree with him, but the problem that I discussed was somewhat different from his.

I think I do disagree fundamentally with Professor Gilmore. He suggests that law is like language, and therefore we cannot do anything about it. I simply would refuse, in part on faith, to accept this

2 Professor of Economics, Virginia Polytechnic Institute. 
world. I don't like to think the world is hopeless. Now I am going to be very interested to see what the lawyers around here today have to say about this approach. I would not be happy if I thought we were all wasting our time.

There are two aspects of this problem that have not been fully distinguished. One is the degree of riskiness-or flip it over and call it safety-the consumer is to be allowed to bear. And, second, once you agree on that, is the question of how to assign liability. These are two separate problems.

I was trying to examine the effects in these terms of the shift toward more and more liability being placed on the producers, which McKean instanced as being part of our experience. This implies that consumers or buyers are being constrained to purchase products which have inherently less riskiness than would have been true under caveat emptor. I tried to argue that if you ignore third party effects and, temporarily, information problems, this result can be condemned on both equity and efficiency grounds. There would be no conflict between equity and efficiency because the people who suffer in this case are the poor. We condemn this on both equity and efficiency grounds, so the only justification for departure from caveat emptor then is that there may be third party effects.

You can argue a general shift in this direction if you argue that products are more and more exerting third party effects. But if we focus on third party effects and examine each product as a separate category, what does this do to the law? Law by its nature has some generality in it, and if you start talking about particular products and product subcategories, maybe you get into Professor Gilmore's world after all. That does worry me.

Products by and large are getting more complicated. The problem confronting the buyer in choosing amongst competing products is getting more difficult. But this does not in itself justify a departure from caveat emptor. Because of this information problem you can perhaps justify a larger public role in information supply. I have not really developed this fully, but it does seem to me that there is what some economists call a public good aspect to information. It seems to me this might be discharged directly through information supply rather than by trying to accomplish the same thing very crudely and indirectly by a shift toward producer liability.

Guido Galabresi. I think that Professor Buchanan's formulation has a basic error in it. He talks about how much risk consumers should 
be allowed to bear. And, he says, if we have caveat venditor, producer liability, then consumers cannot choose to pay less and take risks. My problem is one of symmetry. If we have caveat emptor, consumer liability, then the poor producer who wishes to take a risk of a product which causes injury, because he likes to take risks, is deprived of that opportunity. In the theoretical model that Professor Buchanan poses of a large number of consumers, there may also be a large number of producers, and there is no particular reason to assume that one of these risk-taking groups is more important than the other. None of this would matter, of course, if we had no transaction costs. We need not keep repeating that; in addition, it would not matter too much if we had some transaction costs if we allowed what are called exculpatory or indemnificatory agreements. That is, it is not the decision about whom we put the liability on in the first place that diminishes choice in Buchanan's model. The problem of diminution of choice arises only if we forbid transactions to shift the initial burden. But in the first instance, one is as good as the other for this purpose.

The difficulties arise since transaction costs may make exculpatory clauses too difficult to establish. The moment we come to this point we have to decide who is going to be liable. Whose risk-taking do we want to maximize? Do we want to give more chance to risky producers or more chance to risky consumers? That is the kind of empirical question about which I think Professor McKean quite properly says there would be disagreement. It all depends on how you look at it, on what you think is important.

Beyond this, often the law not only places initial liability on the producer but also bars exculpatory clauses. Then we have in effect decided that we do not want consumers to take risks. When we do this, we usually do it because we think that we have problems of information costs. I think we might profitably spend some time on why it is that as we have moved from the world of one man trading face to face with another man, where we certainly did not want to bar any exculpatory clauses, to the world of today, we tend to bar more of these. That is, I think, the crucial issue. There is nothing in theory about either consumer liability or producer liability which increases economic efficiency. The two are as a theoretical matter completely equivalent.

As you start bringing in practical matters, differences begin to appear. It is there that the nuances of Professor McKean's and my paper may be different. I tend to emphasize more those factors which suggest the importance of the choices on the part of producers. None of this can be proven in any economic sense. I suppose we could get 
more empirical data than we have, but I suggest that as lawyers we do not have to wait for proof because we have to make a decision between the two. Professor Gilmore's paper suggests that the choices are being made politically, and the choice is being made precisely in the direction Gilmore suggests.

In addition, Professor McKean suggests that every case of collective decision-making is one of wanting to tell someone else how to behave because we know better. I would suggest that there are times when we make collective decisions on grounds that are really akin to the economic efficiency argument. That is the situation where, because of transaction costs, it is cheaper to do something by a collective decision. We know that this will destroy some choice, but we make the empirical judgment that more important choices are maintained. In effect that is analogous to what we do, given transaction costs, when we decide on either producer or consumer liability.

A more direct case occurs when we bar people from going through a red light. It is very hard to put the cost of running through red lights to them at that point. We cannot do it. So what we do is to recognize that some people might prefer to run the red light if given that choice. But they are so few that by forbidding it we come nearer to what we think would happen if we were able without cost to give everybody his choice. I think there is a whole series of collective decisions whose justification is not that "I know better than you" but that we come closer to what would happen in the world of no transaction costs by making this collective decision than by not making the collective decision.

Robert Dorfman. ${ }^{4}$ The central issue of the whole discussion goes in part to the way that economists on the one hand and lawyers on the other hand seem to look at the problem. We are faced with the diffculty that economics is like the law of gravity in this sense-it works best in a vacuum. The law of gravity works just fine in dealing with objects in orbit way out there. It is not helpful at all in predicting more terrestrial projectories. The problem both for ballistics experts and for economists is that we really are not concerned with problems in a vacuum.

A great deal of economic policy in law and elsewhere is designed for no other purpose than to correct the various imperfections that are experienced in actual markets-transaction costs, information costs, and various other kinds of frictions-many of them quite technical. If you take one of these policies and examine it in the light of a per-

4 Professor of Economics, Harvard University. 
fect economy, in a vacuum, with no information costs or transaction costs, it will usually turn out that that policy will do no good and very likely some harm. Then no one, not even a non-economist, would recommend those policies. But the policies are actually designed to overcome the windage and the frictions and complications that make our world different from the abstract world in which economic theory works most effectively. So the split in our camp is a difference in judgment as to how far we think the inspection of perfect markets can take you in dealing with our specific issue.

Grant Gilmore. 5 I find the economic analysis in the papers not only fascinating but extremely valuable. However, as a lawyer, I would inject a precautionary note against any belief that theoretical understanding of so complex a phenomenon can be a guide for action. We may feel that if we can develop a theory which everybody believes to be correct and if the theory tests out empirically, then we lawyers should draft a statute reflecting the conclusions arrived at or at least formulate a statement to guide judges so that they could arrive at better decisions. But I doubt strongly and instinctively-and that is the part of my paper which so saddens Professor Buchanan-that there really is any carryover, even from the most correct understanding of what transpires in the real world, to what ought to be done about it as a matter of law reform. As Professor Calabresi remarked, the process of law reform or law change is essentially political not technological.

The principal point I tried to suggest in my comments on Professor McKean's paper was that the developments that appear to have been going on in this isolated field of products liability have been part of a much larger phenomenon with the same reversal of risks between active and passive parties. It has occurred across the whole spectrum of our law of civil obligations. It has been going on over a long period of time and is essentially a political process.

I assume that the economists are on the whole opposed to this development. Let us further assume that they can be proved to be correct, not only in the other world of the Coase theorem but in the real world. What follows? Suppose it was a statute implementing the correct conclusions which the economists have drawn with respect to products liability. That would move developments in this area in the opposite direction from the course which instinctively has been followed in all other areas of obligation over the last fifty to seventy-five years. This would, I think, set up intolerable strains within the legal

5 Professor of Law, The University of Chicago. 
system. One cannot isolate for action-although one can profitably isolate for analysis and description-a field as narrowly circumscribed as this.

George Stigler. ${ }^{6}$ I should like to start by complaining against the anti-theoretical attitude of all of the speakers. They are playing a game, popular in fields like labor-economics, but which I hope would not get a foothold here, of erecting a very formal theoretical model and then saying once you depart from it a couple of inches nothing is left. The theory has enormous real vitality, as I shall try to illustrate. You could take a surface, a uniform space, and distribute resources and preferences over it, and assume (1) zero transportation costs and (2) any assignment of the costs of adjustment of space, that is, of locating yourself as either a buyer or a seller. You quickly get to the result that it does not matter where you assign the latter responsibility in this regime of zero transportation costs. If now you introduce transportation costs it still makes no difference where you assign the responsibility for the movement. Furthermore, the movement will be optimal, no matter what the transportation cost, up to and including complete immobility. There is no sense in which the theory loses its validity as you move away from that extreme.

It is similar in the case of products liability, although everybody says that once we put transaction costs in, we are playing in a different ballpark. But that is not so. There are very strong incentives in the economic system to minimize transaction costs, to make the appropriate amount of transactions and not to embark upon unnecessary ones. I find a failure to recognize this, for example, when Calabresi says, "The existence of large transaction costs are obvious in products liability situations where third parties are injured. The cost of gathering all pedestrians who might be injured by an unsafe car or an unsafe driver and getting together to bribe the car makers is obviously enormous." But one of the clever things the economic system does is not engage in those transactions which are never going to occur. It is not expensive to have one unsafe car identified by having it hit somebody and then have the appropriate redress by legal action. So an immense number of transactions never have to be engaged in. When people say that the theory no longer holds once we have departed from the zero transaction case, they are making what $I$ think is an unfounded conjecture.

GALABRESI. Of course, the tendency for the market to minimize transaction costs exists and will minimize the error which our interference,

6 Professor, Graduate School of Business, The University of Chicago. 
our placing of liability, will make. It will minimize it up to the point where the size of the transaction cost makes further changes not worthwhile. And, in this sense, once we have allocated liability, the market will always work best to minimize our mistake. But, if you have transaction costs, where you put the liability in the first place makes a difference.

Stigler. Why does it make a difference to us? You have not proved that. I take it that the assignment of liability is in itself a transactioncost-economizing device, and that you could have no rules of liability and let all people who engage in trades establish them.

Calabresi. One could. We evidently choose to have liability rules because we think that this collective decision is cheaper than these transaction costs. That is another example of the red light situation. We do this throughout society. That is what all legal rules in effect are; that is what I think Professor Demsetz's article on property made quite clear. Now, the problem, I suppose, is to decide which assignment of liability, between the two, is going to get us nearer to what would happen if we did not have transaction costs. That does not mean that once we have done this, but imperfectly, we would not have new, advantageous transactions. But it is as wrong to say that it does not matter where we put liability initially.

Harold Demsetz. ${ }^{8}$ I would like to join Professor Stigler in defending the Coase theorem, but defending it in a different fashion. I think that the theorem is extremely useful for the purpose for which it was set out and also for this conference. The purpose for which it was originally developed was to dispel some nonsense in economics which had nothing at all to do with transaction costs. It had to do with clearly wrong positions about where you assign liability or whether tax methods were appropriate measures of adjustment. In that context it was an extremely powerful theorem.

But, even if we do remove it from that context and place it in the context of this conference, it seems to me that the Coase theorem serves a very useful purpose. There is a lot of naivete about what happens when the courts decide that one person or another is liable. The Coase theorem makes you reconsider simplistic notions about what the effect of the law is going to be. I think that it is a tribute to the Coase theorem that everybody here is now aware of the fact that, until you start playing this game of transaction costs, the law may not

7 Demsetz, Some Aspects of Property Rights, 9 J. LAw \& Econ. 61 (1966) [ed.].

8 Professor, Graduate School of Business and Law School, The University of Chicago. 
have any effect at all. I do not think that people realized that until the Coase proposition was launched.

W. PAge KeEton. ${ }^{9}$ We have talked here about costs as if we knew what they were. You have somebody whose eye is put out by an exploding Coca-Cola bottle; that is the typical products liability case. Now assume with me that that represents a thousand dollar liability. But the system that we are talking about here involves probably a charge of two thousand dollars on the manufacturer. In addition to what it repays under the legal standard which sets the thousand dollar figure, it has to clear its own investigation expense, its own counsel fees, and its own system of prevention and all the rest. Meanwhile, the person whose eye was put out receives only $\$ 500$, since typically in these small claims the contingent fee for the lawyer will run something in the order of $50 \%$ or maybe a little less. But the great bulk of this legal business is done not through courts but through the threat of using the courts and through negotiation between the lawyers. I think it is fair to say that long before the courts changed the law the settlement practices had abandoned the search for fault pretty largely and really just looked to see if the man's eye was really out. I think this is what you mean by transaction costs, but I am never sure because this is an information cost. I do not know if you count that as part of the transaction costs or not. I also do not know whether you are calling the cost of keeping the jury away from other useful work a transaction cost or not. To me the label "transaction cost" does not fit that too well. Part of what is troubling me is that $\mathrm{I}$ do not have a clear picture of just what these costs are.

MELVIN REDER. ${ }^{10}$ I think it is fruitful to consider that each producer of a product is producing a joint product. One would be the product itself; the other would be a liability contract. As a concrete example, when Sears Roebuck sells many of its appliances, it also offers the option of a service contract. In principle one could have a variety of alternative service contracts each of which would, in principle, specify the location and extent of the liability. So Sears or any seller could, in principle, offer a variety of joint products. A customer then selects which among the possible products and combinations he wants. Indeed, legally to assert where the liability must lie is really to limit the possibility of choice among these alternative products. This has disadvantages from the economist's point of view. Once we look at the matter in this way, the information cost really becomes a species of policing

9 Dean and Professor of Law, The University of Texas.

10 Professor of Economics, Stanford University. 
costs and the cost of the uncertainty of how the courts are going to interpret the contract, since you cannot specify exactly what a liability contract will mean in every little case.

One could urge the development of consumer advisory services to tell non-specialized buyers what the contract might mean; conceivably the state might even subsidize legal counseling about the contracts. Perhaps the market for information itself would generate it. I have something of Professor Buchanan's feeling, however, that this may be a place where market failure has a greater than usual chance of appearing. Looked at in this way, it seems to me that one could come much closer than otherwise to caveat emptor. Give the buyer a variety of options from which he may pick and give him free or cheap technical advice and let him go to it. Occasionally, where there are externalities, the state may decide that as a condition of having the product put on the market at all, a certain minimum type of guarantee ought to be required.

ROBErT BrAucher. ${ }^{11}$ As I think of myself drawing up a contract for Sears Roebuck for warranty liability, the difference between that and taking that same provision and putting it in a state statute seems much smaller than economists seem to think it is.

REDER. What you forget is that there is Montgomery Ward, and if Sears puts in a provision that a substantial set of customers do not want, those customers will shift to the outlet that gives them the kind of quality they do want. Your legislature is not that indulgent of minority tastes.

KeEton. On the contrary, quite often in the process of drafting this type of plan Sears Roebuck puts in a provision and Montgomery Ward is likely to follow suit. When they go to the state legislature they are likely to be there together.

REDER. But somebody may not. Somebody may say, "Look, there is still this minority group over here and it would pay us to cater to them."

GILMORE. The statutes in any case would start off: "Unless otherwise agreed ...."

CALABresi. I do not understand why Professor Reder reaches the conclusion that one should start with the rule of caveat emptor with warranties sold to the appliance buyer. One could, I take it, just as well start with the rule of caveat venditor and have exculpatory clauses. If 
you accept what Professor Reder says or what follows from Coase, it does not matter where you start, just as long as you allow this free contract. Then the question focuses on this free contract. Professor Reder suggests that there is a substantial role for the government in policing this free contract and in seeing that this free contract actually is based on adequate information for all the parties. But if you once say that the government ought to step in and make this information available or ought to help people, it is at least conceivable that people's wants are more nearly catered to more cheaply if you come in with a government rule that says you shall not do that.

Now this certainly destroys the desires of some people. But what we have to do as lawyers is compare the loss of these people's choice with the costs of setting up the kind of policing device necessary to make Professor Reder's suggestion work.

Richard MusGrave. ${ }^{12}$ I would distinguish between two entirely different aspects to note about transaction costs. One is the opportunity cost of putting resources into the negotiation or decision process. I do not think this is terribly interesting. The real problem arises because you have small numbers involved in the bargaining process and this may lead to solutions which are quite different from the competitive ones. In other words, the imperfections result from the bargaining process. You have a kind of bilateral situation, and don't know how it is going to come out. It seems to me that the term "negotiation cost" should be used for the differences between the actual outcome and that which would arise if we had a perfectly competitive market process.

STIGLER. Transactions do not have a natural definition. We used to have big fights twenty or thirty years ago over whether you could draw an absolutely sharp line between production costs and selling costs. That literature petered out with the conclusion that you could not make such a distinction except in polar cases. The simplest kind of transaction would be an exchange of one clearly valid currency for another clearly valid currency at a currency exchange. There are almost pure transaction costs in this exchange of titles. There are almost no costs of research for the validity of the product and so forth, and it is all very clean.

But in ordinary consumer product transactions there are services performed, and the transaction does not end the day that the title transfer takes place. There may be continuing latent responsibilities, and there may be continuing contractual relationships influenced by this initial contract. Thus, the contrast between a transaction cost and 
a non-transaction cost is an empirical rather than a purely formal classification.

Demsetz. If by great good luck you are put into an optimal position, then it would not matter if it cost a great deal to move or not because you do not have any desire to move. By transaction costs here we are talking about those costs of being in a non-optimal position that it does pay to bear. I agree with Stigler that we attempt to minimize them, but I do not agree that where we start from does not matter. The legal system that starts you in a very bad position costs more than a legal system which starts you close to the optimal position. It seems to me that the notion of transaction costs refers to the lesser of these two costs, one of which is not merely a cost of movement or transaction but a cost of the non-optimality which may be less than the movement cost, a kind of opportunity cost.

CALABRESI. Is not the crucial question whether this movement is accomplished best be leaving it up to the market or to some kind of collective rule? Demsetz says it is a matter of good luck to be there in the first instance, but it might be a matter of having more intelligence. Suppose bad luck puts us in a particular position but the market would not get us to a better position because it is too expensive. We then make a judgment, which involves comparisons of utility, that we can by coercion, by a legal rule, move from that position to another one. And we may decide to do that because we think that is more efficient than staying where we are, though there is then the problem that once some collective decisions are accepted, other collective decisions, not based on efficiency notions, become more likely.

Braucher. One of the great cases in the products liability field is the Henningsen case. And, one of the things that motivated the court was precisely that General Motors, Ford, and Chrysler used the same products liability system which put all the costs on the ordinary consumer who buys a car, and they had done it by what was called a "free contract." It was no more a free contract than a statute is a free contract, but there it was. Now, as I understand the Coase theorem, it says that if General Motors, Ford, and Chrysler get together to put the entire load of products liability on the consumer, then as long as there are no transaction costs, that would not affect resource allocation. Well, if that is true, then I submit further that if all of the people who drive cars and own cars get together and get the legislature to put the burden back on General Motors and Ford and Chrysler, there is also no effect on resource allocation and that we should go to some other question. 
WILLIAMI KLEIN. ${ }^{13}$ I would like to bring up a point which might give some sort of framework for all of this, the distinction in products liability between a sale by the manufacturer of an automobile and a sale by an individual. Suppose that I sell my car to somebody else, that it is eight years old, and that I know from experience that cars that are eight years old have brake failure, among other things; but I do not know specifically that anything is wrong with this car. If the brake linings fail a month later and the buyer is injured, I take it that the rule is quite clear that that buyer does not have a cause of action against me. On the other hand, if General Motors sells cars knowing that in the course of manufacture there will be a number of cases in which brake linings fail, General Motors is liable.

Dean Keeton says that the explanation that fits this situation is that General Motors is in a better position to spread the risk-to take out insurance-than is the individual. I do not agree. I would say that the individual is in a better position to spread the risk because he can decide for himself what his own life is worth, whether or not he wants protection against accidents, and so forth. But, it seems fair to me to say that if companies like General Motors tell people that here is a marvelous, hotsy-totsy car and do not give them an option to buy insurance policies or a better car that has been inspected more, I think it very reasonable to say, "O.K., we are going to take you at your word as it appears in all your advertising rather than in this little contract that you have given us."

Braucher. In McKean's paper there is a reference to the automobile liability schemes, and I think also to the workmen's compensation scheme, but we have not seen how the apparatus we have been discussing would work in a non-traditional legal arrangement.

CALABRESI. Well, the workmen's compensation scheme would look the following way: Assume a world in which there is employee liability for work-associated accidents. In order to maintain a given quality of labor, as a first approximation, employers have to pay wages that are high enough to reimburse the employees for the costs of accidents that they are likely to incur. So the employer has an incentive to economize on accidents. If he economizes on accidents, he reduces his wage bill, since the actuarial wage equivalent he would have to pay would be reduced if he economized on accidents. Now take the liability scheme and switch it over, making the employer liable for accidents -work-associated accidents-or making him buy insurance to cover work-associated accidents. He pays an actuarial premium to the insur-

13 Professor of Law, University of Wisconsin. 
ance company to cover the work-associated accidents and, at a first-level approximation, in order to get the same given quality of labor, he now has to pay a correspondingly lower wage rate. So that in either situation, at the first-level approximation, there is no difference as regards the accident rate; in both cases you have the same financial incentive to economize on accidents.

BrAUCHER. As Gilmore said, if you have a general trend in your society to make the big industrial corporations liable for everything in sight, it is simply not possible to carve out a little thing called "products liability" and say that it is going to be different. There is a certain tendency for everything to work together in this same general way, and if that is what happened with workmen's compensation first, and we are now getting to where automobile accidents are going to be on the no-fault scheme or social insurance scheme or something, it sticks in my mind that products liability is going to go along with that trend too.

WALTER BLUM. ${ }^{14}$ I wonder whether anybody thinks that in any major industry the differential transaction costs from going one way or another on products liability make any significant difference. Are we not talking about something that in the overall picture of cost allocation is relatively trivial? It really does not matter much which way it comes out. Is it likely that there are a significant number of circumstances in which putting the liability originally on the manufacturer or seller as against putting it on the user is likely to make a significant difference, assuming that the law does not prohibit contracting out of it?

CALABresr. I am puzzled by one thing, because you telescoped again the question of initial liability and the question of contracting out of it, and I think we cannot attack the problem you pose unless you pull these two things apart. The question of initial liability would have to be whether this is the kind of defect which, either because of risk-awareness or because of the existence of transaction costs, is one which the manufacturer can more cheaply avoid. If instead, you move to the question of whether a liability-shifting contract is to be allowed or not, then you are immediately faced with the question of whether the consumer has made a conscious or adequate choice that he wishes to bear this particular type of risk. And this leads you right back to the difference between the situations where the defect is known and where the defect is knowable and the degree of riskawareness of the parties. Where the consumer has made a conscious

14 Professor of Law, The University of Chicago. 
choice, consumer liability would seem to offer an attractive scheme. But because of the tendency of people to insure, we must also consider the expense of making insurance categories which are sufficiently differentiated and personal. Because of that expense we find that very often a collective method of control-a non-insurable fine, jail, the whip, hanging, any nice thing, or driver's license removal-is a more effective way of controlling consumer behavior.

When we move to the manufacturer's side, we may find that there the market works surprisingly effectively because there each company is its own insurance population. It can respond to the risk. If true, this would be a good reason for choosing producer liability. We must also consider Professor McKean's point that, on what might be called "fairness grounds," society may require consumer recoveries or social insurance of some sort, so that no one is rendered destitute or his income level changed dramatically as a result of accidents. Then the choice realistically may be between a system like social insurance, paid out of taxes, which has a totally different economic effect, and a system of manufacturer liability, which there are some of us who would say might even improve matters economically. There are some who might say it may make matters worse, but certainly it is clear that it would not be as undesirable in efficiency terms as social insurance. I think that is the battle that is going to be fought.

McKean. I would like to give a brief reaction to Professor Blum's question. It does seem to me that there are instances in which it might make considerable difference which way you assign the liability, even allowing for contracting out or internalizing some of the burdens. I think drugs may be a case of a product where it makes a difference which way you assign liability. This may well be a case in which, if you change the liability drastically from consumer to manufacturer's liability without fault (even though he can then contract out by insurance and so on), there would be a considerable difference in the total costs of accidents, the accident rates and total costs.

Marshalc Shapo. ${ }^{15}$ Recently I was in the back yard on a Sunday afternoon with my little boy who just turned five. He cut his finger, ran into the house and came out a couple of minutes later wearing a bandaid. When I went back in the house, I found an open medicine cabinet that I had not considered he could reach. So I would like to pose a specific question: I am a judge with a case of a five-year-old child who has killed himself by taking too many aspirin from an aspirin bottle that does not have the safety-lock cap. I want to know

16 Professor of Law, The University of Texas. 
what the economic consequences are of holding the aspirin manufacturer for not having this kind of cap.

MusGrave. It seems to me that where no variation in the product's safety is possible, one can better afford to be indifferent about where the burden should lie. But where greater safety can be provided at relatively little cost by the manufacturer, as in this aspirin bottle case, one would prefer manufacturer's liability. The manufacturer is more likely to know the possibilities of technical change in the product which will affect safety than is the consumer. There are really two things: one is the insurance problem given the risk characteristics; and the other is the effect of changes in the product on the level of accidents. Placing the liability on the manufacturer will make him respond more effectively by introducing safety features because he knows the technology which is involved in doing this.

Demsetz. There is a simple way to handle it: give the choice to the consumer. You can have cheaper aspirin bottles which thoughtful and intelligent parents will put where no child can reach them, and you can have those for the careless and superficial and label them accordingly, and let people buy the kind they want.

SHAPo. That assumes one can distinguish between a class of intelligent people and a class of careless people. There is really only one class of people and they are occasionally intelligent and careful and occasionally negligent, but they are the same people all the time.

CALABREST. If I were presenting that case [assuming that the object were only economic efficiency], I would say, first: "Your Honor, if you do not become convinced that it makes any difference which way, in terms of economics, we put this liability, let me suggest that there is a great deal of pressure on equity, justice, and whatever grounds, to move towards social insurance which covers all these accidents. Such a move clearly would make a very substantial efficiency difference, because it would remove this cost both from the careless parent and from the careless manufacturer. Because this pressure will increase if we have consumer liability, you should put the burden of proof on the economist to convince you that consumer liability is more efficient than producer liability." Then I would ask whether it is cheaper to have an arrangement which lets a parent choose a cheaper bottle which he can put in a higher place, or the opposite. If there is suffcient information, we feel confident that the choice will be made intelligently. If the cost of giving this information is too great, we may choose not to allow this kind of transaction. You would first have 
to decide how much information and what kind of information would be required in order to be confident that we were really dealing with people rationally choosing to buy a cheaper product because as to them it was sufficiently safe. Then the inconvenience cost for people to find out which aspirin bottle was safest as against the cost of making a safer bottle would become the principal question.

In order to make the case more interesting, we might allow contracting out of liability only if the contract met certain requirements of information. Then the cost of meeting such requirements might be so great that whichever way we put the initial liability, it would actually stay, because no one could meet the requirements for a contract.

StIGLER. You play a one-sided game. We talked about how the market acquires information and how people react to it, but on the other hand you seem to presume that the legislature gets free, accurate, and immediate information on new developments and that it has an effcient bureaucracy to enforce its policies.

Demserz. It seems to me that in this kind of example there is inevitably a disagreement among people about whether or not they should be protected from themselves, in other words whether or not you want to interfere with their choices, and I think that is probably present here. The people that Mr. Shapo has in mind are probably the kind that Professor Gilmore mentioned, and it includes a lot of us who are intelligent part of the time and have some lapses. The question is, are we smart enough to hedge against the contingencies by buying the more careful product, or do we deliberately take the other, or do we take it without thinking? On this sort of thing I do not see any way to resolve a disagreement. "There are two types of people," as the old saying goes, "those who agree that there are two types of people and those who don't." And some people believe in interfering with other people's choices and some people do not.

WALTER Or. ${ }^{16}$ Suppose simply that the government faces the decision of whether or not to insist on safety caps. The government really does not know what the reduction is in the probability of an accidental death, and that might be very slight. It is misleading then to talk about an individual instance where some child actually commits the fatal act. What you must ask is how much safety caps reduce the probability or the expected loss for a typical customer as against the cost we impose on buyers of aspirin by insisting on the caps. When you put it

\footnotetext{
16 Professor, Graduate School of Management, University of Rochester.
} 
in this kind of probabilistic terms, I do not see any clear direction in which you ought to move.

CALABresi. You have made a jump, because by putting liability on the manufacturer we do not quite insist on safety caps. Let us assume we do put liability on the manufacturer and that an adequate exculpatory contract is too expensive. At that point we have not compelled the cap. We have compelled the manufacturer to choose between paying the damages, plus the administrative costs entailed in the damages, and putting on the cap. The government may be capable of forcing this choice when it is not capable of making the collective decision: "You must use the cap."

Buchanan. May I make a comment on this, not so much as an economist, but maybe a little in support of Professor Gilmore? It seems to me that we slipped too quickly into talking about the government making this decision. We were talking about the case as posed. We are talking about the single judge faced with this problem, and, obviously, from this discussion, no matter what kind of evidence the judge is going to get, it is going to be conflicting. So the judge makes a decision, and he makes a decision somehow on the basis of these costs and benefits, and on the basis of his own judgment. This seems to me to be a pretty good way of solving this, provided we do not have a centralized court that uniquely decides this for everyone for all time. This is a strong argument for allowing a judicial system which has decentralized decision centers in which one judge is free to decide one way, and another in a different way. The emergence of law out of this kind of context might well be justified in the sense of a provisional way of arriving at an answer about which nobody is certain.

SHAPO. A year or so ago a study was made of Chicago's schoolchildrenI think the sample was about thirty thousand-and it was found that 757 had toxic levels of lead in their bodies, presumably from housepaint. There is a strong feeling that we should find ways of preventing such occurrences, of protecting children against these hazards, which, after all, result from products with which they had no contractual connection in any sense. What does the economist have to contribute to the judgment that has to be made about an issue like this?

CALAbrest. I am not an economist, but I want to put one thing which you said in context. You suggested that we want to protect people in some way. I would put that same notion in a slightly different way. People in some ways like to protect themselves against themselves. We may not like this, but it is a recurring phenomenon. We pass a Bill of 
Rights in our Constitution so that when we are tempted at a particular moment to enact some laws which violate something which in a calmer moment we felt was important, we protect ourselves from the temptation. There is at least one sense in which a system of liability rules may be this kind of thing, a protection designed at a calm moment. When I go into a polling booth I may not want all people to have to do certain things. But I may want them to force me, perhaps, to buy medical insurance, even though as a result I force other people who may not want it. The majority of us require this because we find it necessary to protect ourselves against a later moment when the trip to Florida looks like an awfully good idea.

I am not quite sure how you handle this; I do not think that the discussion has addressed this question at all, and I think it is in large part behind Shapo's query. It is not that these people are incompetent; it is that they themselves will vote to protect themselves against a subsequent incompetence.

Demsetz. I would accept Professor Calabresi's point-you can derive a certain logic for some legislation or liability rules as people somehow protecting themselves. But I think Shapo meant something quite different. He seemed concerned with the widely held view that some people are simply incompetent to judge their own well-being and incompetent to choose as consumers. Therefore, it is incumbent on us, as on the rest of the community, to impose standards which will in fact prevent them from doing themselves damage. It may well be that we are forced to that sort of position, but $I$ think we ought to be clear that it is completely contradictory to accept that view. If we start worrying about our liability laws on the presumption that some people are incompetent, how can we then go along and say that those same people should be allowed to vote for liability rules or a government, which is a far more complicated problem than purchasing food. If we start talking about our liability laws in that context, we must examine the whole logic of political democracy. Now, if you are willing to go that farand I am not-I have to fall back and say that I assume that people are intelligent enough to make their own decisions.

KEETON. I think it is not a question of intelligence or competence on the part of the people. But it is certainly true that each of us is limited in what he can learn about. Now in most instances it seems to me perfectly clear that the manufacturer who makes his product has to know more about the risk and the incidence of harm that is likely to result from his product than anybody else. If you assume that he is going to pass all this on and that the consumers can drink in all the information 
that comes from a thousand different sources, well, then you assume something that is completely irrational. They cannot know about it; it is impossible for them to learn about it; I do not care how smart they are. But the manufacturer knows about his product.

ARMEN ALChIAN. ${ }^{17}$ I have heard the statement made often that consumers just do not appreciate the risks they are faced with. But consider the fact that 500 people get killed every year flying in airplanes. Does that mean that people undervalue the risk of flying an airplane? Not at all. People are ignorant and realize that information is expensive. Just because one man knows something someone else does not know does not mean that he is going to use the information to someone else's benefit. The economic problem is to produce the amount of information people want.

The automobile warranty provides a beautiful illustration, and it would affect everybody in this room. We are all intelligent, over-educated people, literate and logical, and none of us, I will bet, has read with understanding the warranty on his automobile. This contract is freely made, with no coercion, and everybody in the United States buys a car this way. The contract says that if the steering wheel should come loose in your hands and you should run off a cliff and if you should take the defective part, if there is one, and send it back to Detroit, freight prepaid, and if this happens before you have had the car ninety days or three thousand miles, whichever happens first, and if in the sole judgment of General Motors, Ford, or Chrysler, it agrees that the part was defective, it will supply you a new part and charge you only for labor.

Stigler. The warranty does not consist of that piece of paper; it consists of a set of practices of the manufacturer, his agents and dealers when product defects are displayed to them. Let us not let the difficulty of wording a contract so that it does not crucify one party disguise the fact that economic reality consists of a set of practices that are actually engaged in.

GILMORE. Which are quite contrary, of course, to what they have said earlier. Of course, the practice of the manufacturer after the steering wheel broke in poor Mrs. Henningsen's hands was to say "sure, we will take care of this."

KEETON. This information gap reminds me of some of the cases in medical malpractice holding that a doctor does not have to explain all of the details involved in surgical procedures. I do not want my doctor

17 Professor of Economics, University of California at Los Angeles. 
trying to explain all of that to me. I would not understand him-and I would rather just have him go ahead and do what he thinks he ought to do and get it over with.

HENRY G. MANNE. ${ }^{18}$ There is some confusion here because one group is, I think, assuming that the pieces of paper you have with writing on them are part of the information; the economists, $I$ think, are talking about information which is an operative factor in everyone's decisionmaking, viewed in the aggregate. If pieces of paper do not affect anyone's action or anyone's wealth decision, they are not a relevant part of the information process for the economist.

REDER. Part of what the economists have been saying is in fact what the students have been saying. No "in loco parentis." What we are saying is that, given the way that people get information, they are going to do as good a job, as far as they are concerned, as some other person or agency can do for them. However poor this may be, the alternative to having individuals make their own individual decisions is to have them made by some other mechanism, and in general what we are saying is that in practice most people will indicate that they think this is inferior. The cigarette-smoking case is, I think, the classic example.

Shapo. I want to come back to the paint case, which is a third party case in which the injured party is not one of the contracting parties. It seems to me that the no-in-loco-parentis argument does not apply there and I want to know what help an economist can give me in making a normative judgment on that problem.

DEMSETZ. Let us approach the problem generally rather than specifcally. We would like to go on the premise that freedom of action is something that is good. We would like to have it produced, but it is not producible without costs. One of the costs of producing freedom is that people are going to make mistakes in using their freedom. Even from their own viewpoint they are going to make mistakes.

If we approach the system from that viewpoint, we next ask who is going to make decisions for children. As a general rule we feel that children's self-interest will on the average be best taken care of if we allow the decisions to rest in the hands of their parents, knowing at the same time that some parents are going to make mistakes. We feel that if we tried to bring up the children in government camps, we would make worse mistakes of a different kind.

It is not a question of no mistakes versus some mistakes, it is a question of having mistakes of one kind versus mistakes of another kind.

18 Professor of Law, Department of Political Science, University of Rochester. 
Obviously no one has perfect knowledge. Somehow you must decide when you are going to stop trying to rectify the mistakes that arise from people's exercise of freedom. And maybe the line is not drawn in the right place, maybe you want to shove it one way or another, but merely citing the fact that some people have made mistakes that have hurt third parties is not in itself a convincing argument to me that we ought to draw the line someplace else.

Alchian. Economic theory does not tell what you ought or ought not to do; it merely points out the consequences of actions that you choose for reasons based on other criteria. But do not ask the economists or economic theory what you ought to do; they will never tell you. All they can do is to avoid common fallacies as well as give you other implications that you had not foreseen.

MusGrave. It seems to me that economists can say a little more than that. Suppose these children who had this toxic poisoning did not have it from the painting of their own house, but, let us say, from paint in the neighborhood, so that we do not make the children the third party with their parents the first party. It is a real third party case. Then, it seems to me, the situation is one where the use of this paint has a certain externality which is overlooked by the market because the people who buy this paint do so at the cost of producing this paint. The cost of the damage to children is overlooked. I think the economist in this case can say that this is a market failure, that the cost of this externality should be allowed for and that there should be, say, a cost in the form of an excise tax on the production of that paint. Now, whether the proceeds of that excise tax should be used to make restitution payments to the children is what I call the problem of fairness. The economist can certainly say that the consumers of the paint ought to pay the external cost of their using it.

Peter Steiner. ${ }^{19}$ I would even say a little more than Mr. Musgrave. The economists know two things: They know that sometimes markets work, and they know that sometimes markets fail. I think they know some of the circumstances under which the probability of failure is likely and when there may be some case for interference. It seems to me in general that we economists are not in the position to say simply that freedom is in general always preferred to any alternative when in fact we know that in some cases interfering is more likely to result in a more desirable result. Though we cannot solve the normative question, we can define the conditions under which a market failure is likely to

10 Professor, Department of Economics and Law School, University of Michigan. 
occur. I do not know where that line would be drawn, but I would urge that we get some work done on this.

GALABRESI. Let us take the paint case in the third party situation. I suppose if all the people who are likely to be injured by this paint were aware of their risk and could get together and bribe the manufacturer, they would pay the manufacturer not to make this kind of paint. Obviously that is absurd. The costs of that are too great and that is what we mean by saying that that is an externality. Even so we have a choice to make, because the moment we decide that this is one of those situations where we put the liability on the manufacturer, no paint will any longer have lead in it. We will have deprived some people, who would have been able to use leaded paint in situations where it might harm no one, of that opportunity. That is some deprivation. On the other hand, if we fail to put liability on the manufacturer, we are inducing all manufacturers to produce leaded paint because it is cheaper and because they do not have to bear the real cost because the transaction cost of putting that full cost on them is too great. So this poses, in a somewhat more dramatic way, precisely the question we all have been talking about. With third parties the question as to who has the lowest costs of cost avoidance must be faced. I think most people judge the cheapest cost avoider in that situation to be the paint manufacturer. If economists could come up with a good deal of information we might convince the public of the opposite. At the moment, however, whether economists like it or not, that is where the burden of proof rests, because uninformed people, who are not going to spend money to inform themselves, guess on this empirical question that way.

MusGrave. There are all types of legislation which have been passed to protect children. A classic case is, of course, forced education. All children must go through this process because we do not trust the parents to invest in the children. Our society has been quite prepared to go into the family and attempt to control the relationship between parents and children in a very extensive fashion, as illustrated in education or in child labor legislation. Certainly we have made this judgment without the fear that thereby we have tremendously constrained freedom.

The historical change in the law which we have talked about may be a function of the economic progress that we have. As we move into an increasingly affluent society, there is a tremendous growth in the amount of goods and purchases of commodities. Time is the scarce factor. Yet, with the growth in wealth one must make a great many more decisions, and the time available for decisions is becoming more 
and more valuable. We may be prepared to pay more for information, but with the increase in the number of goods, the cost of information will mount considerably, while the payoff for any given improvement, any given commodity, is relatively small. In other words, the increased value to you of being able to choose more intelligently between $A$ and $B$ is relatively small, while the costs of making informed decisions are increasing. We may therefore be increasingly prepared to accept the judgment of the government or some other group who will do the screening, provide us with information, guarantee the safety of the products, etc., even though this involves some cost in terms of reducing the range of available commodities. 